\title{
Influence of surgical approach on heterotopic ossification after total hip arthroplasty - is minimal invasive better? A case control study
}

Maya Hürlimann ${ }^{1,3+}$, Filippo-Franco Schiapparelli ${ }^{1,3+}$, Niccolo Rotigliano ${ }^{1,3}$, Enrique Testa ${ }^{1}$, Felix Amsler ${ }^{2}$ and Michael T. Hirschmann ${ }^{1,3^{*}}$

\begin{abstract}
Background: Heterotopic ossification (HO) is a well-known complication after total hip arthroplasty (THA). Recently, the trend is to operate THA minimally invasive being less traumatic than standard approaches and promising a faster return to activity. The purpose of the study was to investigate if minimal invasive surgery (MIS), leads also to less HO after THA.

Methods: This retrospective study included 134 consecutive patients undergoing THA. In 42 (31.3\%) patients a standard modified anterolateral (STD-Watson-Jones), in 28 (20.9\%) patients a standard transgluteal Bauer approach (STD-Bauer), in 39 (29.1\%) a MIS direct anterior approach (AMIS) and in 25 (18.7\%) patients a MIS anterolateral (MIS-AL) approach was used. Standard preoperative anterior-posterior and lateral radiographs were assessed for occurrence of HO. HO was classified according to Brooker. In addition, short- and long-term adverse events were noted. Data was statistically analyzed using Chi-square tests, analysis of variance, multivariate data analysis and Pearson's correlation $(p<0.05)$.

Results: Overall, HO was found in 38 caucasian patients (28.4\%) after THA. The STD-Watson-Jones group showed the highest $\mathrm{HO}$ rate $(45.2 \% n=19)$ with a significant difference to the AMIS $(23.1 \% n=9)$ and STD-Bauer approach $(14.3 \% n=4)$. No statistical difference was found to the MIS-AL approach $(24.0 \% n=6)$. Postoperative complications did not differ significantly except for a higher incidence of Trendelenburg's sign in STD-Bauer.

Conclusions: The rate and degree of $\mathrm{HO}$ after THA were significantly different with regards to the surgical approach. The standard modified anterolateral approach resulted in the highest HO rate, however, MIS approaches showed higher $\mathrm{HO}$ rates than the STD-Bauer.
\end{abstract}

Keywords: Heterotopic ossification, Anterolateral minimal invasive approach, Watson-Jones, Periarticular ossification, Total hip arthroplasty, THA, Transgluteal Bauer, Direct anterior approach

\footnotetext{
* Correspondence: michael.hirschmann@ksbl.ch

${ }^{\dagger}$ Equal contributors

'Department of Orthopaedic Surgery and Traumatology, Kantonsspital

Baselland (Bruderholz, Liestal, Laufen), CH-4101 Bruderholz, Switzerland

3University of Basel, Basel, Switzerland

Full list of author information is available at the end of the article
} 


\section{Background}

Heterotopic ossification (HO) is a well-known complication after total hip arthroplasty (THA) with a reported mean incidence of $24-32 \%$ [1-9]. There is only scarce evidence about the influence of the surgical approach on $\mathrm{HO}$ occurrence. Not more than two different approaches have yet been simultaneously compared in terms of $\mathrm{HO}$ $[10,11]$.

Although $\mathrm{HO}$ etiology remains unclear, it has been postulated that osteoinductive growth factors are released as consequence of soft tissue trauma inducing the formation of $\mathrm{HO}[12-14]$. $\mathrm{HO}$ is believed to reach its complete formation after 6 to 12 weeks post-operative and not to progress anymore after this period [15]. Symptoms vary dependent on the severity of $\mathrm{HO}$, and range from local pain to reduced range of hip motion $[16,17]$. The Brooker's classification grades $\mathrm{HO}$ into four different grades [18]. Most of the cases of $\mathrm{HO}$ belong to grade I and II and generally run asymptomatic being a collateral finding in routine follow-up radiographs [19]. A less incidence of patients present severe $\mathrm{HO}$ classified as grade III and IV, with more hip pain and significantly reduced ROM, flexion, abduction, and external rotation of the hip when compared to grades 0 , I and II $[15,20]$.

In modern THA a considerable number of surgical approaches are used. Besides the conventional standard approaches, minimally invasive surgery (MIS) approaches are increasingly used. These MIS approaches promise less gluteal insufficiency, a faster rehabilitation and a quicker return to normal daily life activities $[1,21]$.

The primary purpose of the present study was to investigate the influence of the following surgical approaches on $\mathrm{HO}$ : minimally invasive anterolateral (MIS-AL), minimally invasive anterior (MIS-AMIS), standard transgluteal (STD-Bauer), and the standard modified anterolateral (STD-Watson-Jones). The secondary purpose was to investigate if minimally invasive surgery (MIS) leads to less $\mathrm{HO}$ than standard THA approaches.

\section{Methods}

All patients who underwent primary THA in the period 2012-2013 in a university affiliated hospital with a minimum follow-up of 12 months and a signed informed consent were included in the present study. Patients without a preoperative and postoperative (at a least of 12 months) radiological control on radiographs and patients who did not sign the informed consent were not included. Indications for surgery were end-stage osteoarthritis and traumatic neck fractures. In this period the standard THA done was an uncemented Zweymüller type stem and a pressfit cup (Smith\&Nephew, Switzerland).
In this period, four consultant surgeons of the same department performed a total of four different surgical approaches. Patients have been divided according to the performed surgical approach, standard modified anterolateral (STD-Watson-Jones) (group A), standard transgluteal Bauer approach (STD-Bauer) (group B), direct anterior minimally invasive (AMIS) (group C) and anterolateral minimally invasive (MIS-AL) (group D) (Table 1). The choice of the surgical approach was based on the preference of each surgeon.

In order to evaluate the $\mathrm{HO}$ onset and compare its incidence across the groups, pre-operative and 1-year post-operative radiological images (antero-posterior and lateral) were compared using a radiological display monitor (Fig. 1). The Brooker's classification system was used (Table 1) [18].

Patients' demographics including age, gender, relevant comorbidities (e.g. diabetes mellitus, cardiovascular diseases, osteoporosis, previous hip surgery) were noted. Intraoperative, early and late complications were obtained from the hospital archives system (KIS, Erne, Switzerland). The average time of hospital stay was calculated from hospital archives data.

Early mobilisation with full weight bearing was initiated under physiotherapeutic supervision on the first postoperative day. The postoperative protocol was identical for all groups.

\section{Statistical analysis}

All data were analyzed by an independent statistician (F.A.) using SPSS version 17.0 (SPSS Inc., Chicago, IL, USA). Continuous variables were described using means and standard deviations or medians and ranges. Categorical variables were tabulated with absolute and relative frequencies. In the groups A-D no significant differences were seen in terms of gender, age and relevant comorbidities $(p<0.05)$. Univariate analysis was performed using Pearson's correlation to identify any correlations between the type of approach, demographic and outcome variables. ANOVA analysis was also done for each variable. Multivariate analysis (MVA) was performed for $\mathrm{HO}$ incidence, occurred complications and time of hospital stay. To analyze a direct relationship between surgical approach and $\mathrm{HO}$, all influencing additional factors were excluded (osteoporosis, fractures, dislocations, Trendelenburg`s sign/ muscular deficit, muscular deficits, urinary tract infection) and a MVA was performed including all the results that showed univariate significance. Multivariate analysis used a stepwise linear regression of all variables on the dependent variable surgical approach. $p<0.05$ was considered statistically significant and $p<0.1$ as a statistical tendency. 
Table 1 Patient demographics as well as $\mathrm{HO}$ and complications divided by the type of THA approach used

\begin{tabular}{|c|c|c|c|c|c|c|}
\hline & & \multicolumn{4}{|l|}{ Approach } & \multirow[t]{3}{*}{ Tota } \\
\hline & & \multicolumn{2}{|l|}{ Standard } & \multicolumn{2}{|c|}{ Minimally invasive } & \\
\hline & & $\begin{array}{l}\text { STD } \\
\text { Watson-Jones }\end{array}$ & $\begin{array}{l}\text { STD } \\
\text { Bauer }\end{array}$ & AMIS & MIS-AL & \\
\hline \multicolumn{7}{|l|}{ Gender } \\
\hline \multicolumn{2}{|l|}{ Men } & 21 & 16 & 22 & 10 & 69 \\
\hline \multicolumn{2}{|l|}{ Women } & 21 & 12 & 17 & 15 & 65 \\
\hline \multicolumn{2}{|l|}{ Mean age } & 42 & 28 & 39 & 25 & \\
\hline \multicolumn{7}{|c|}{ Comorbidities } \\
\hline \multicolumn{2}{|c|}{ Previous THA } & 14 & 12 & 12 & 7 & 45 \\
\hline \multicolumn{2}{|c|}{ Diabetes mellitus } & 5 & 5 & 7 & 5 & 22 \\
\hline \multicolumn{2}{|c|}{ Cardiovascular diseases } & 24 & 15 & 22 & 15 & 76 \\
\hline \multicolumn{2}{|c|}{ Osteoporosis } & 5 & 1 & 1 & 3 & 10 \\
\hline \multicolumn{7}{|l|}{$\mathrm{HO}$} \\
\hline \multirow[t]{2}{*}{ Grade 0} & Count & 23 & 24 & 30 & 19 & 96 \\
\hline & $\%$ & $19,0 \%$ & $3,6 \%$ & $7,7 \%$ & $12,0 \%$ & \\
\hline \multirow[t]{2}{*}{ Grade 1} & Count & 8 & 1 & 3 & 3 & 15 \\
\hline & $\%$ & $19,0 \%$ & $3,6 \%$ & $7,7 \%$ & $12,0 \%$ & \\
\hline \multirow[t]{2}{*}{ Grade 2} & Count & 5 & 2 & 4 & 1 & 12 \\
\hline & $\%$ & $11,9 \%$ & $7,1 \%$ & $10,3 \%$ & $4,0 \%$ & \\
\hline \multirow[t]{2}{*}{ Grade 3} & Count & 3 & 0 & 2 & 1 & 6 \\
\hline & $\%$ & $7,1 \%$ & $0,0 \%$ & $5,1 \%$ & $4,0 \%$ & \\
\hline \multirow[t]{2}{*}{ Grade 4} & Count & 3 & 1 & 0 & 1 & 5 \\
\hline & $\%$ & $7,1 \%$ & $3,6 \%$ & $0,0 \%$ & $4,0 \%$ & \\
\hline \multirow[t]{2}{*}{ Total } & Count & 42 & 28 & 39 & 25 & 134 \\
\hline & $\%$ & $31,3 \%$ & $20,9 \%$ & $29,1 \%$ & $18,7 \%$ & \\
\hline \multicolumn{2}{|c|}{ Mean Stay in hospital } & 42 & 28 & 39 & 25 & \\
\hline \multicolumn{2}{|c|}{ Intraoperative complications } & 4 & 3 & 1 & 0 & 8 \\
\hline \multicolumn{7}{|c|}{ Early complications } \\
\hline \multicolumn{2}{|l|}{ Bleeding } & 1 & 2 & 0 & 0 & 3 \\
\hline \multicolumn{2}{|c|}{ Wound healing problems/infection } & 4 & 1 & 1 & 4 & 10 \\
\hline Cardiovas & & 1 & 1 & 4 & 0 & 6 \\
\hline Pulmonar & & 0 & 0 & 1 & 0 & 1 \\
\hline Postoper & & 42 & 28 & 39 & 25 & 134 \\
\hline Urinary tr & & 5 & 1 & 0 & 0 & 6 \\
\hline Late compli & & & & & & \\
\hline Fracture & & 3 & 1 & 1 & 1 & 6 \\
\hline Dislocatio & & 0 & 2 & 1 & 0 & 3 \\
\hline Loosenin & & 1 & 0 & 0 & 0 & 1 \\
\hline Leg lengt & & 9 & 9 & 14 & 7 & 39 \\
\hline Trendeler & $r$ deficits & 10 & 10 & 3 & 2 & 25 \\
\hline Local sen & ain & 7 & 5 & 9 & 6 & 27 \\
\hline Revision & & 2 & 2 & 1 & 3 & 8 \\
\hline
\end{tabular}



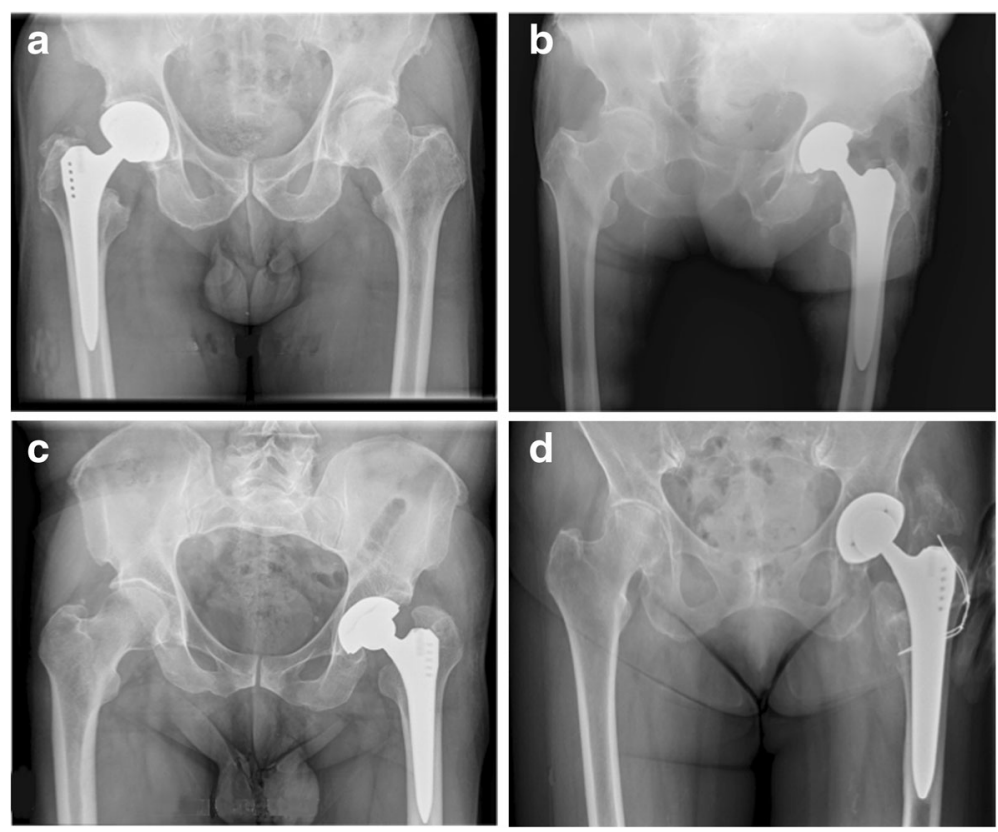

Fig. 1 One year follow-up standard radiographic control, examples of heterotopic ossification according to Brooker grade 1 (a), grade 2 (b), grade 3 (c) and grade 4 (d)

\section{Results}

One hundred thirty-four consecutive caucasian patients fulfilled the inclusion criteria. Forty-two patients (31.3\%) were included in group A, 28 patients (20.9\%) in group B, 39 patients $(29.1 \%)$ in group $\mathrm{C}$ and 25 patients (18.7\%) in group D (Table 1). HO was found in $28.4 \%$ of the patients with the highest incidence in group A (45.2\%) followed by group D, (24.0\%), group C (23.1\%) and group B (14.3\%) (Table 1). According to the Brooker's classification, among the $28.4 \%$ patients who developed HO, $11.2 \%$ had a grade I, $9.0 \%$ a grade II, $4.5 \%$ a grade III and $3.7 \%$ a grade IV (Table 1) (Fig. 1a-d). Focusing on grade III and IV since they are the ones with clinical relevance: group A showed the highest $\mathrm{HO}$ rate, 14.2\% (7.1\% each for grade III and grade IV) followed by group D, $8.0 \%$ (4\% each for grade III and grade IV); group C, 5.1\% (5.1\% grade III) and group B with an $3.6 \%$ incidence (3.6\% grade IV) (Table 1$)$. Group A developed significantly more $\mathrm{HO}$ than group $\mathrm{B}(p=0.020)$ and group $\mathrm{C}(p=0.038)$. Group $\mathrm{A}$ and group $\mathrm{D}$ showed no significant difference in terms of HO rate $(p=0.095)$. Multivariate analysis showed that group A explained 5.0\% of the factor "HO". In addition, the presence of osteoporosis explained $3.8 \%$ of the factor "HO". Overall, these two factors explained unadjusted $8.8 \%$ of the HO. Data about intraoperative, early and late complications are presented in Table 1. Urinary tract infection was significantly higher in group A $(11.9 \%, n=5)$ in comparison to group $C(0.0 \%, n=0 ; p=0.022)$ and group $\mathrm{D}(0.0 \%$, $n=0 ; p=0.009)$. No statistical significant difference was seen in comparison to group B. $(3.6 \%, n=1, p=$ 0.095). The most frequent late complication was leg length discrepancy with an incidence of $29.1 \%$ in the overall study cohort. There was a significant difference between the groups $(p<0.01)$ for Trendelenburg`s sign indicating gluteal muscle insufficiency. It was seen in $35.7 \%$ of group B, $23.8 \%$ in of group A, $7.7 \%$ of group C and $8.0 \%$ of group D (Table 1). The average stay in hospital was 11.1 days (range 4-56 days) (Table 1). Patients in group $C$ had a mean stay in hospital of 9.1 days, which was significantly shorter than group A (12.1 days), group B (11.5 days) and group D (12.1 days) (Table 1). The univariate Pearson's correlation of all variables is shown in Table 2.

\section{Discussion}

This is the first study comparing four different THA approaches in terms of $\mathrm{HO}$. So far, only two types of surgical approaches were simultaneously compared. The overall incidence of $\mathrm{HO}$ in this study was $28.4 \%$. Toom et al reported an $\mathrm{HO}$ incidence of $32 \%$ in 178 patients who underwent THA using a posterolateral approach [5]. Pavlou et al. noted an incidence of $24 \%$ in 39 patients who underwent THA using a STD-Watson-Jones approach [2]. Yanbin Zhu et al. reported a similar HO rate $(30 \%)$ in a metanalysis involving 14 studies with a total of 6468 patients. However, the type of THA approach was not specified [4]. In summary, the overall $\mathrm{HO}$ incidence in the present study is in line with the previously reported $\mathrm{HO}$ rates in the published literature. 


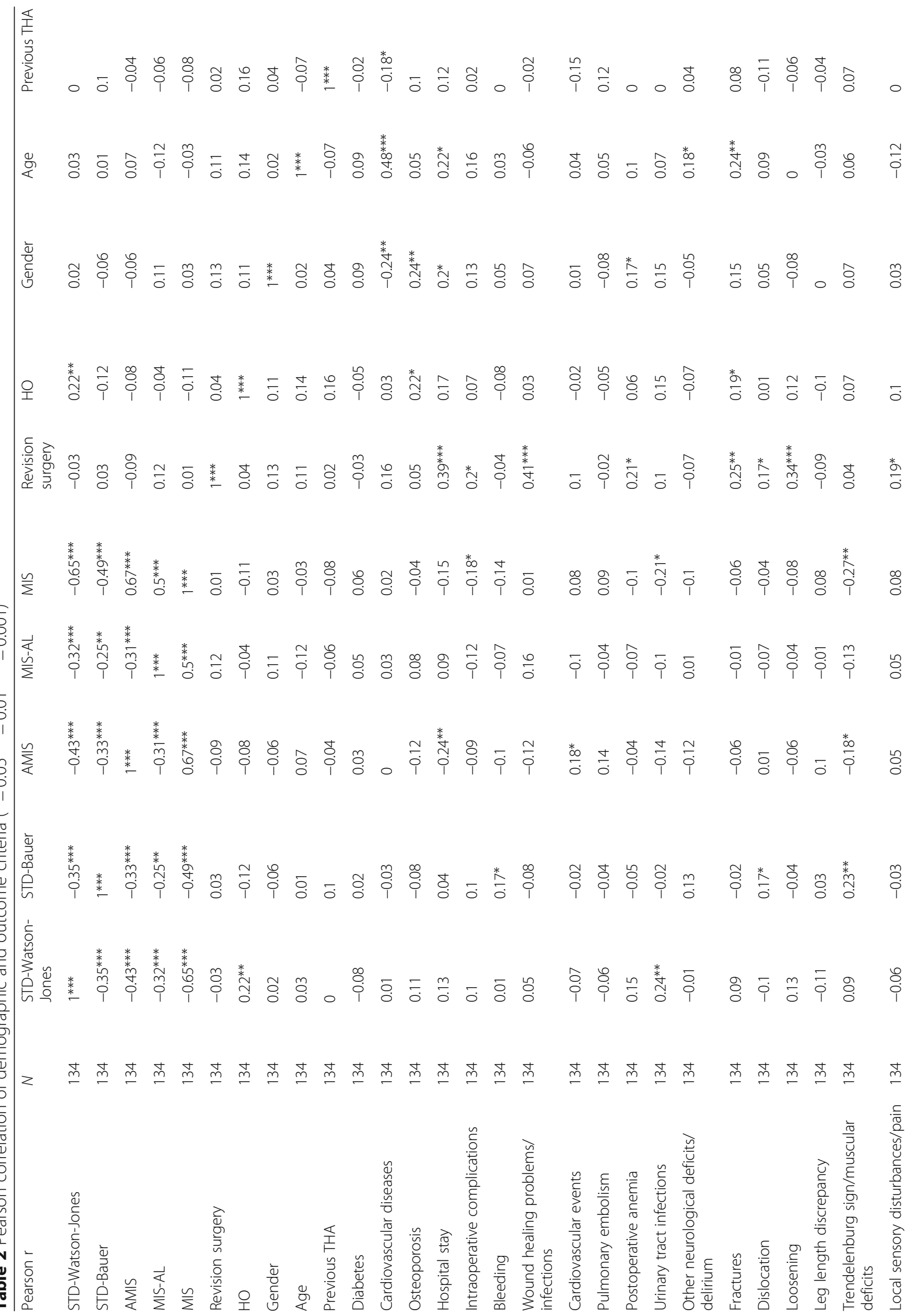


莃

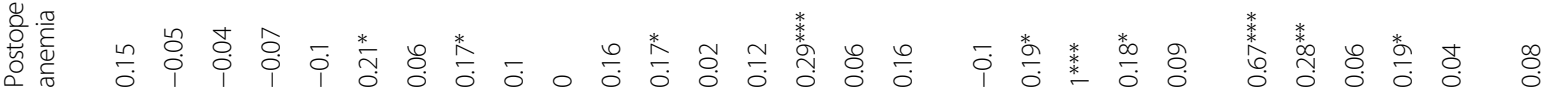
斊 $\frac{\varepsilon}{\tilde{c}}$

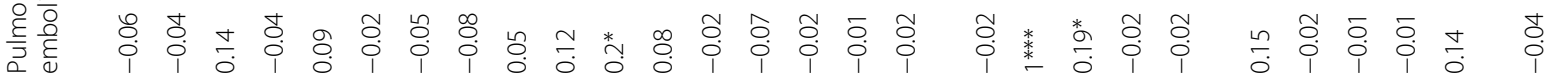

$\frac{\bar{c}}{3}$

褐 ס

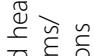

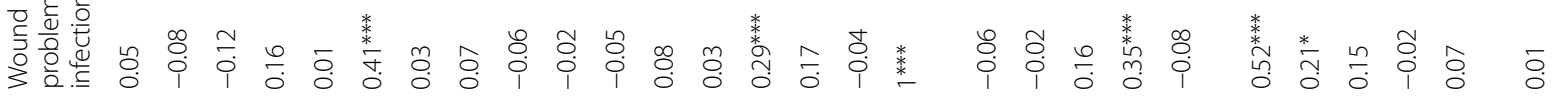
or

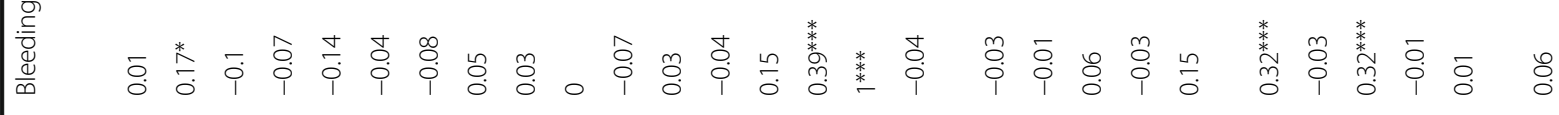

䲶

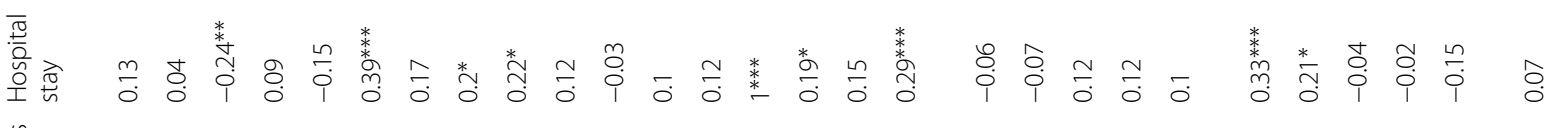
$\frac{\sqrt{2}}{\frac{\pi}{0}}$

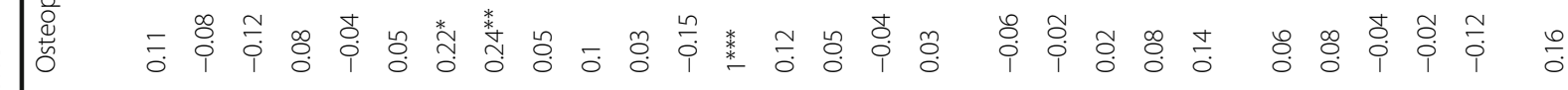

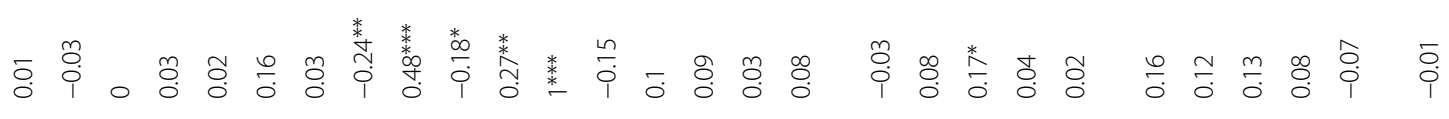

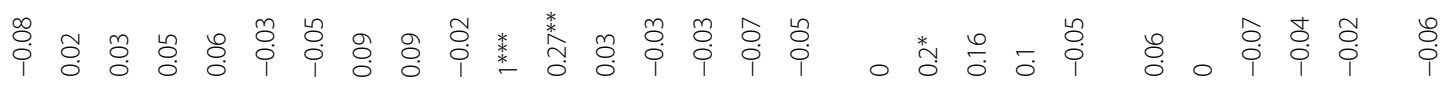
잉 
(a)

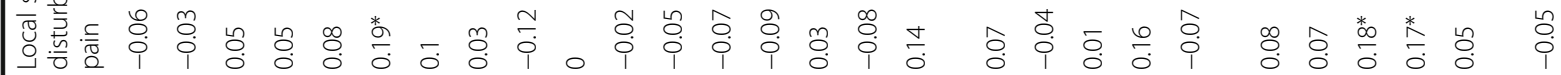
焉范

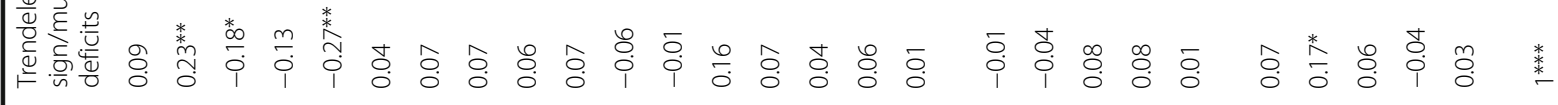
衰䆑

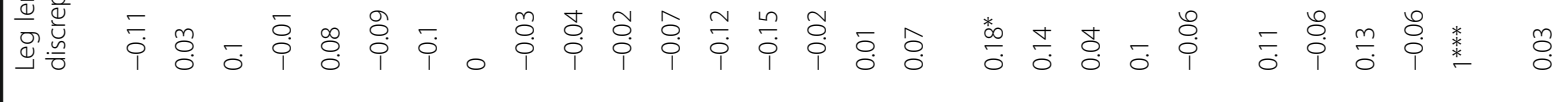

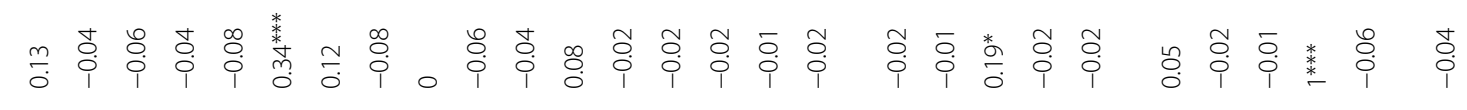

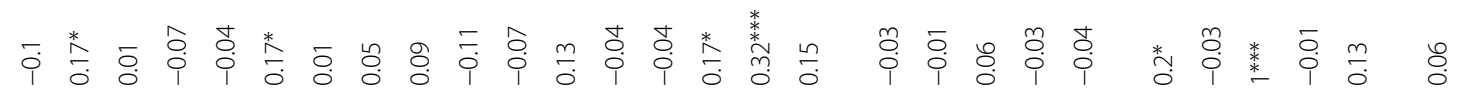

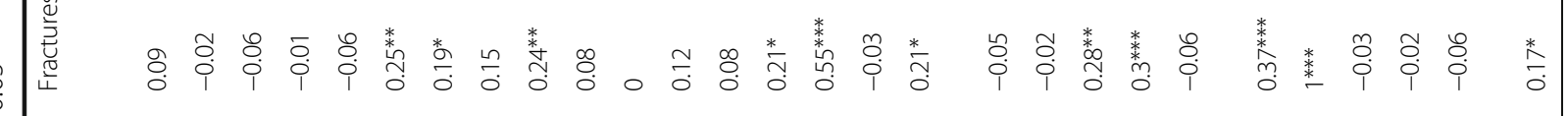
* 厄)

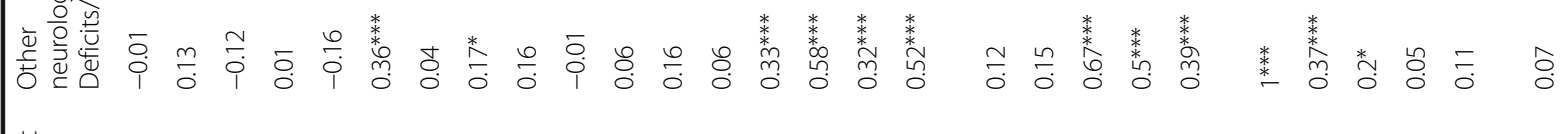

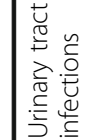

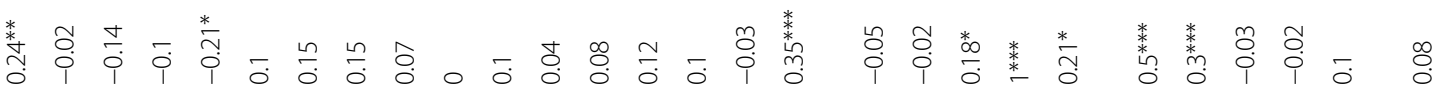

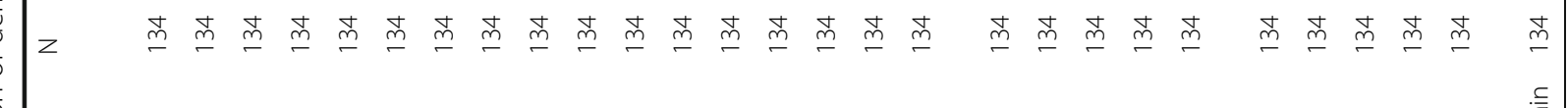


The most important finding of the present study was that the rate and degree of $\mathrm{HO}$ after THA was significantly dependent from the surgical approach used. The STD-Watson-Jones approach showed a significantly higher $\mathrm{HO}$ rate than the STD-Bauer and AMIS approaches. This was also higher than the MIS-AL approach but without any statistical significance. This last finding has been also noted by Repantis et al. [10]. In contrast to the present study Biz et al. found a higher $\mathrm{HO}$ rate for the STD-Bauer approach $(p=0.0163)$ when compared to the STD-Watson-Jones [11]. These different results could be related to the different type of used implants that included also patients who underwent a hemiprothesis. To date, there is not a single study comparing the $\mathrm{HO}$ rate of patients who underwent THA using the STD-Watson-Jones and AMIS approach. With regards to $\mathrm{HO}$ rates in patients after THA using the AMIS approach, the results are conflicting. Whereas Tippets et al. reported a $\mathrm{HO}$ rate of $41.5 \%$, [22] which is higher than in the present study, Newman et al. reported a $\mathrm{HO}$ rate of $24.3 \%$ [6], which is comparable with this study. It could be speculated if the reason for the highest $\mathrm{HO}$ rate in the STD-Watson-Jones group lies in the more traumatic dissection, which is clearly less invasive using a MIS approach. A recent study of Unger et al. [23] found that the AMIS approach for THA comes along with less muscle damage and hematoma, shorter operative and exposure time, less bleeding and faster rehabilitation time. Although the highest $\mathrm{HO}$ rate was seen in the STD-Watson-Jones group, it was not possible to state that minimally invasive approaches lead to less HO. Indeed, both AMIS and MIS-AL had a higher $\mathrm{HO}$ incidence than the STD-Bauer. This finding remained unexplained.

In this study the lower complications' rate with MIS (MIS-AL, AMIS) than with the standard techniques (STD-Bauer, STD-Watson-Jones) reflects the current knowledge and are considered as advantages of MIS as shown by Unger et al. [23]. However, among the complications, only the Trendelenburg sign was statistically significant for which the MVA showed an increased risk in the STD-Bauer group.

Another important finding of this study was the direct comparison of the stay in hospital among the four approaches. Patients who underwent THA using an AMIS approach had the shortest mean hospital stay. However, the average stay in hospital of the MIS-AL group was probably distorted by a patient, who developed an early infection, has been three times operated and remained in the hospital 56.0 days. The stay in hospital difference between AMIS and the STD-Watson-Jones was the only statistically significant difference.

So far, no study compared four surgical approaches for a THA with regards to the hospital stay. Ilchmann et. al.
[24] noted a significantly shorter stay in hospital after the AMIS approach compared to the STD-Bauer approach. Yue et. al. found similar results in a metaanalysis [25]. However, the average stay in hospital was 9.1 days for the AMIS and 11.5 days for the STD-Bauer approach (Table 1). All together MIS approaches for THA appear to be beneficial in terms of $\mathrm{HO}$ as well as adverse events. Hence, if possible MIS approaches should be used. In conclusion, this study has proven the general superiority of MIS approaches in terms of $\mathrm{HO}$ and adverse events.

A considerable number of limitations need to be considered. The most important one is the retrospective study design. The possible selection bias was however limited by the consecutive patient selection.

Four different orthopedic surgeon operated on the patients reported and choose the approach with regards to their own preference, which might have influenced the outcome in each group. However, all surgeons were capable to perform all four different approaches. As it was the aim to focus on $\mathrm{HO}$ after THA no clinical outcome data was assessed. Furthermore, only patients with $\mathrm{HO}$ grades 3 and 4 were included. Patients, who developed complications during couse of treatment were also included, which could have led to a longer stay in hospital as well as increased $\mathrm{HO}$ development.

The major strength of the study presented is that it is the first study investigating $\mathrm{HO}$ onset in four different THA approaches. In addition, it represents a consecutive patient series with a good and balanced sample size.

\section{Conclusion}

This is the first study comparing the STD-WatsonJones, STD-Bauer, AMIS and MIS-AL approaches in terms of $\mathrm{HO}$. The rate and degree of $\mathrm{HO}$ after THA was significantly dependent from the surgical approach used. The STD-Watson-Jones presented the highest $\mathrm{HO}$ rate. A lower complications' rate was seen after minimally invasive approaches. Hence, if possible MIS approaches should be used. In conclusion, this study has proven the general superiority of MIS approaches in terms of $\mathrm{HO}$ and adverse events.

\section{Abbreviations}

AMIS: Minimally invasive direct anterior approach; HO: Heterotopic ossifications; MIS: Minimal invasive surgery; MIS-AL: Minimally invasive anterolateral; MVA: Multivariate analysis; STD-Bauer: Standard transgluteal Bauer approach; STD-Watson-Jones: Standard modified anterolateral WatsonJones approach; THA: Total hip arthroplasty

\section{Funding}

This study received no funding.

Availability of data and materials

All data supporting our findings are contained in the manuscript. 


\section{Authors' contributions}

Study conduct: MH, FFS, MTH. Data collection: MH, ET, NR. Data analysis: FA. Data interpretation: MH, FFS. MTH. Drafting manuscript: FFS. Revising manuscript content: FFS MTH. Approving final version of manuscript: $\mathrm{MH}$, FFS, NR, ET, FA, MTH takes responsibility for the integrity of the data analysis.

\section{Competing interests}

The authors declare that they have no competing interests.

\section{Consent for publication}

Not applicable.

\section{Ethics approval and consent to participate}

This work has been approved by the ethical committee "Ethikkommision beider Basel EKBB". Informed consent was obtained from all individual participants included in the study. All procedures performed in studies involving human participants were in accordance with the ethical standards of the institutional and/or national research committee and with the 1964 Helsinki declaration and its later amendments or comparable ethical standards.

\section{Author details}

'Department of Orthopaedic Surgery and Traumatology, Kantonsspital Baselland (Bruderholz, Liestal, Laufen), CH-4101 Bruderholz, Switzerland. ${ }^{2}$ Amsler Consulting, $\mathrm{CH}-4059$ Basel, Switzerland. ${ }^{3}$ University of Basel, Basel, Switzerland

Received: 5 July 2016 Accepted: 11 January 2017

Published online: 21 January 2017

\section{References}

1. Spinarelli A, Patella V, Petrera M, Abate A, Pesce V, Patella S. Heterotopic ossification after total hip arthroplasty: our experience. Musculoskelet Surg. 2011;95(1):1-5.

2. Pavlou G, Salhab M, Murugesan L, Jallad S, Petsatodis G, West R, Tsiridis E. Risk factors for heterotopic ossification in primary total hip arthroplasty. Hip Int. 2012;22(1):50-5.

3. Schara K, Herman S. Heterotopic bone formation in total hip arthroplasty: predisposing factors, classification and the significance for clinical outcome. Acta Chir Orthop Traumatol Cech. 2001;68(2):105-8.

4. Zhu Y, Zhang F, Chen W, Zhang Q, Liu S, Zhang Y. Incidence and risk factors for heterotopic ossification after total hip arthroplasty: a metaanalysis. Arch Orthop Trauma Surg. 2015;135(9):1307-14.

5. Toom A, Haviko T, Rips L. Heterotopic ossification after total hip arthroplasty. Int Orthop. 2001;24(5):323-6.

6. Newman EA, Holst DC, Bracey DN, Russell GB, Lang JE. Incidence of heterotopic ossification in direct anterior vs posterior approach to total hip arthroplasty: a retrospective radiographic review. Int Orthop. 2015;40(9):1967-73.

7. Aljurayyan A, Tanzer D, Tanzer M. Acute revision hip arthroplasty: a previously unrecognized risk factor for heterotopic ossification. Eur J Orthop Surg Traumatol. 2016;26(2):183-8.

8. Harwin SF. Trochanteric heterotopic ossification after total hip arthroplasty performed using a direct lateral approach. J Arthroplasty. 2005;20(4):467-72.

9. Bal BS, Lowe JA, Gietler A, Aleto TJ. Heterotopic ossification after 2-incision total hip arthroplasty. J Arthroplasty. 2010;25(4):538-40.

10. Repantis T, Bouras T, Korovessis P. Comparison of minimally invasive approach versus conventional anterolateral approach for total hip arthroplasty: a randomized controlled trial. Eur J Orthop Surg Traumatol. 2015;25(1):111-6.

11. Biz C, Pavan D, Frizziero A, Baban A, lacobellis C. Heterotopic ossification following hip arthroplasty: a comparative radiographic study about its development with the use of three different kinds of implants. J Orthop Surg Res. 2015;10(1):176

12. Sneath RJ, Bindi FD, Davies J, Parnell EJ. The effect of pulsed irrigation on the incidence of heterotopic ossificiation after total hip arthroplasty. J Arthroplasty. 2001;16(5):547-51

13. Nilsson OS, Persson PE. Heterotopic bone formation after joint replacement. Curr Opin Rheumatol. 1999;11(2):127-31.

14. Chalmers J, Gray DH, Rush J. Observation on the induction of bone in soft tissue. J Bone Joint Surg Br. 1975;57(1):36-45.
15. Board TN, Karva A, Board RE, Gambhir AK, Porter LM. The prophylaxis and treatment of heterotopic ossification following lower limb arthroplasty. J Bone Joint Surg Br. 2007;89(4):434-40.

16. Engelhardt Lexikon Orthopädie und Unfallchirurgie. http://www.lexikonorthopaedie.com/pdx.pl?dv=0\&id=01559.

17. Neal B. Effects of heterotopic bone formation on outcome after hip arthroplasty. ANZ J Surg. 2003;73(6):422-6.

18. Brooker AF, Bowerman JW, Robinson RA, Riley LHJ. Ectopic ossification following total hip replacement. Incidence and a method of classification. J Bone Joint Surg Am. 1973;55(8):1629-32.

19. Kocic M, Lazovic M, Mitkovic M, Djokic B. Clinical significance of the heterotopic ossification after total hip arthroplasty. Orthopedics. 2010;33(1):16.

20. OECD. Health at a Glance 2013: OECD Indicators. In. OECD Publishing; 2013. http://dx.doi.org/10.1787/health_glance-2013-en.

21. Alecci V, Valente $M$, Crucil M, Minerva M, Pellegrino CM, Sabbadini DD. Comparison of primary total hip replacements performed with a direct anterior approach versus the standard lateral approach: perioperative findings. J Orthop Traumatol. 2011;12(3):123-9.

22. Tippets DM, Zaryanov AV, Burke WW, Patel PD, Suarez JC, Ely EE, Figueroa NM. Incidence of heterotopic ossification in direct anterior total hip arthroplasty: a retrospective radiographic review. J Arthroplasty. 2014;29(9):1835-38.

23. Unger AC, Schulz AP, Paech A, Jürgens $\mathrm{CH}$, Renken FG. Modified direct anterior approach in minimally invasive hip hemiarthroplasty in a geriatric population: a feasibility study and description of the technique. Arch Orthop Trauma Surg. 2013;133(11):1509-16.

24. Ilchmann T, Gersbach S, Zwicky L, Clauss M. Standard transgluteal versus minimal invasive anterior approach in hip arthroplasty: a prospective, consecutive cohort study. Orthop Rev. 2013;5(4):e31.

25. Yue C, Kang P, Pei F. Comparison of direct anterior and lateral approaches in total hip arthroplasty: a systematic review and meta-analysis (PRISMA). Medicine (Baltimore). 2015:94(50):e2126.

\section{Submit your next manuscript to BioMed Central and we will help you at every step:}

- We accept pre-submission inquiries

- Our selector tool helps you to find the most relevant journal

- We provide round the clock customer support

- Convenient online submission

- Thorough peer review

- Inclusion in PubMed and all major indexing services

- Maximum visibility for your research

Submit your manuscript at www.biomedcentral.com/submit
Biomed Central 